\title{
Nigerian foodstuffs with prostate cancer chemopreventive polyphenols
}

\author{
Sunday Eneojo Atawodi \\ From The Science of Global Prostate Cancer Disparities in Black Men \\ Jacksonville, FL, USA. 27-29 August 2010
}

\begin{abstract}
Dietary polyphenols are antioxidants that can scavenge biological free radicals, and chemoprevent diseases with biological oxidation as their main etiological factor. In this paper, we review our laboratory data vis-à-vis available literature on prostate cancer chemopreventive substances in Nigerian foodstuffs. Dacryodes edulis fruit, Moringa oleifera and Syzygium aromaticum contained prostate active polyphenols like ellagic acid, gallate, methylgallate, catechol, kaempferol quercetin and their derivatives. Also Canarium schweinfurthii Engl oil contained ten phenolic compounds and lignans, namely; catechol, p-hydroxybenzaldehyde, dihydroxyphenylacetic acid, tyrosol, p-hydroxybenzoic acid, dihydroxybenzoic acid, vanillic acid, phloretic acid, pinoresinol, secoisolariciresinol. In addition, tomatoes (Lycopersicon esculentum Mill) which contains the powerful antioxidant and anti-prostate cancer agent, lycopene; cabbage (Brassica oleracea) containing indole-3-carbinol; citrus fruits containing pectin; Soursop (Annona muricata) containing annonaceous acetogenins; soya beans (Glycine max) containing isoflavones; chilli pepper (Capsicum annuum) containing capsaicin, and green tea (Camellia sinensis) containing (-) epigallocatechin gallate (EGCG), (-) epicatechin, (-) epicatechin-3-gallate and (-) epigallocatechin -3-gallate which are widely reported to posses prostate cancer chemopreventive compounds are also grown in Nigeria and other African countries. Thus, the high incidence of prostate cancer among males of African extraction can be dramatically reduced, and the age of onset drastically increased, if the population at risk consumes the right kinds of foods in the right proportion, beginning early in life, especially as prostate cancer has a latency period of about 50 years.
\end{abstract}

\section{Introduction}

Cancer is a debilitating disease that has afflicted a good proportion of the world population in all generations. According to recent estimates by the WHO [1], annual cancer incidence in sub-Saharan Africa is 551,200 with a mortality of 421,000 . Out of these cases, prostate cancer constitute $24 \%$, and is the fifth most common of all cancers. It is the cancer with the highest incidence, and consequently, responsible for the highest mortality rate of all cancers among black males in sub-saharan Africa. With this unenviable status in the black race, prostate cancer deserve every possible attention with respect to control, prevention and therapy.

Correspondence: atawodi_se@yahoo.com

Biochemistry Department, Ahmadu Bello University, Zaria, Nigeria
According to Adhami et al[2], prostate cancer is an ideal candidate disease for chemoprevention because it is typically diagnosed in men ages $>50$ years and has a high latency period, and hence, even a slight delay in the progression of this disease by chemopreventive intervention could result in a substantial reduction in the incidence of the disease and, more importantly, improve the quality of life of the patients. Epidemiological and laboratory evidence also indicate that the differences in incidence of cancers, in general, and prostate cancer in particular [3], may be associated with the presence of certain polyphenols, especially flavonoids in the diets of these populations [4]. In this paper, we review our research data vis-a-vis published information on cancer chemopreventive polyphenols in Nigerian foods with particular reference to those that have been reported to be active against prostate cancer.

\section{()




\section{Materials and methods Chemicals and reagents}

Chemicals and reagents are of HPLC grade obtained from either Merck (Darmstadt, Germany). Serva (Heidelberg, Germany), Aldrich Chemie (Steinheim, Germany) or Fluka (Buchs, Switzerland). Standard phenolic compounds were obtained from laboratory stock maintained at German Cancer Research Centre, Heidelberg, Germany. All reagent solutions were made in double-distilled water.

\section{Sample and sample extraction}

Sun-dried food samples were acquired from retail outlet in Zaria, Kaduna State, Nigeria in July, 2004. The samples were prepared, stored and extracted with methanol on Soxhlex apparatus following prior extraction with hexane as previously reported [5,6]. Extraction of the Canarium schweinfurthii Engl fruit oil was achieved by solvent-solvent extraction [7].

\section{Analytical high performance liquid chromatography and liquid chromatography-electrospray ionization mass spectrometry}

This was conducted on a Hewlett-Packard (Agilent Technologies, Waldbronn, Germany) model 10980 liquid chromatograph (Latex, Eppelheim, Germany). Chromatographic separation was conducted using a C-18 reversephase (particle size, $5 \mu \mathrm{m})$ column $(25 \mathrm{~cm} \times 2 \mathrm{~mm}$ i.d.; Latex). For separation of individual compounds in the extract, $2 \%$ acetic acid in water (solvent $\mathrm{A}$ ) and methanol (solvent B) were used as mobile phase when $20 \mu \mathrm{L}$ of the extract was injected. The solvent gradient consisted of $95 \%$ A for 2 minutes, $75 \%$ A in 8 minutes, $60 \% \mathrm{~A}$ in 10 minutes, $50 \% \mathrm{~A}$ in 10 minutes, and $0 \% \mathrm{~A}$ until completion of the run at 45 minutes. The flow rate of the mobile phase was maintained at $1 \mathrm{~mL} /$ minute (and $0.5 \mathrm{~mL} / \mathrm{Min}$ ute for liquid chromatography-electrospray ionization mass spectrometry), and phenolic compounds in the eluate were detected with an ultraviolet dual-array detector (HP1040M, Hewlett-Packard) set at 278 and $340 \mathrm{~nm}$ for analytical HPLC. For liquid chromatography- electrospray ionization mass spectrometry, the analyses were conducted in the negative ion mode under the following conditions: dry gas (nitrogen) flow rate, $10 \mathrm{~L} /$ minute; nebulizer pressure $=30 \mathrm{psi}$, drying gas temperature $=$ $350^{\circ} \mathrm{C}$; capillary voltage $=2,500 \mathrm{~V}$; fragmenter voltage $=$ $100 \mathrm{~V}$; mass range $=50-3,000 \mathrm{Da} .2$. Instrument control and data handling were by means of HP Chemstation (Hewlett-Packard) operating in the Microsoft Windows (Redmond, WA, USA) software environment. The amount of phenolic compounds in the extracts was estimated by the external standard method $[5,6]$.

\section{Antioxidant activity and radical scavenging activity}

The hypoxanthine/xanthine oxidase assay system the 2deoxyguanosine assay models were adopted to evaluate the antioxidant and radical scavenging capacity of the extracts [5-7]. The amounts of extracts producing the IC50 for these model systems were determined using the Table Curve Program (Jandel Scientific, Chicago, IL, USA), and the result expressed as $\mu \mathrm{L}$ from $5 \mathrm{~g} / 10 \mathrm{~mL}$ solution; $1 \mu \mathrm{L}=0.5 \mathrm{mg} \times 0.5$ (dilution factor).

\section{Gas chromatography-mass spectrometry analysis}

Analyses were performed on a HP 5973 mass spectrometer coupled to a HP 6890 gas chromatograph. Prior to GC-MS analysis, dried methanolic extracts $(1 \mu \mathrm{L})$ were derivatized by addition of BSTFA $(100 \mu \mathrm{L})$ at $37^{\circ} \mathrm{C}$ for 30 minutes. Separation of the analytes was achieved using an HP 5MS capillary column $(30 \mathrm{~m} \times 0.25 \mathrm{~mm}$ i. d; $0.25 \mu \mathrm{m}$ film thickness). Helium was used as the carrier gas with a linear velocity of $0.9 \mathrm{~mL} / \mathrm{second}$. The oven temperature program was as follows: initial temperature, $100^{\circ} \mathrm{C} ; 100-270^{\circ} \mathrm{C}$ at $4^{\circ} \mathrm{C} /$ minute; and maintained at $270^{\circ} \mathrm{C}$ for 20 minute. The gas chromatograph injector temperature was maintained at $250^{\circ} \mathrm{C}$; the transfer line temperature was held at $280^{\circ} \mathrm{C}$. The mass spectrometer parameters for electrospray ionization mode were as follows: ion source temperature, $230^{\circ} \mathrm{C}$; electron energy, $70 \mathrm{eV}$; filament current, $34.6 \mu \mathrm{A}$; electron multiplier voltage, $1,200 \mathrm{~V}$.

\section{Results}

Whereas the methanolic extract of the leaves of $M$. oleifera Lam. contained chlorogenic acid, rutin, quercetin glucoside, and kaempferol rhamnoglucoside, the root and stem barks contained several procyanidin derivatives. Using the xanthine oxidase model system, the extracts exhibited strong in vitro antioxidant activity, with $\mathrm{IC}_{50}$ values of 16 , 30 , and $38 \mu \mathrm{L}$ for the roots, leaves, and stem bark, respectively, while potent radical scavenging capacity was observed with the 2-deoxyguanosine assay model system, with $\mathrm{IC}_{50}$ values of 40,58 , and $72 \mu \mathrm{L}$ for the leaves, stem bark, and root, respectively. Methanolic extract of Dacryodes edulis fruit on the other hand contained gallate, methylgallate, catechol, ellagic acid, quercetin and quercetin rhamnoside, which were detectable with HPLC-MSD with no additional compound peaks found by GC-MS analysis when extract was derivatized with BSFTA. Gallate occurred in the highest amount while quercetin was present in the least quantity $(0.11 \mathrm{mg} / \mathrm{kg})$. Dacryodes edulis fruit showed high inhibitory effect on the xanthine oxidase system $(\mathrm{IC} 50=14 \mu \mathrm{L})$, but the radical scavenging capacity was rather poor $\mathrm{IC}_{50}$ value $(357 \mu \mathrm{L})$ when analyzed with the 2-deoxyguanosine-assay system. Canarium 
Table 1 Cancer Chemopreventive Polyphenols in some Nigerian Foodstuffs

\begin{tabular}{|c|c|c|c|}
\hline $\begin{array}{l}\text { S/ } \\
\text { No }\end{array}$ & $\begin{array}{l}\text { Food } \\
\text { (Common Names) }\end{array}$ & $\begin{array}{l}\text { Foods } \\
\text { (Botanical } \\
\text { Names) } \\
\end{array}$ & Polyphenol Composition \\
\hline 1. & $\begin{array}{l}\text { African pear, African } \\
\text { plum }\end{array}$ & $\begin{array}{l}\text { Dacryodes edulis } \\
\text { fruit }\end{array}$ & Gallate, methylgallate, catechol, ellagic acid, quercetin and quercetin rhamnoside \\
\hline 2. & $\begin{array}{l}\text { Drumstick, Horse Radish } \\
\text { Tree }\end{array}$ & Moringa oleifera & Chlorogenic acid, rutin, quercetin glucoside, kaempferol rhamnoglucoside, procyanidins \\
\hline 3. & African olive & $\begin{array}{l}\text { Canarium } \\
\text { schweinfurthii Engl }\end{array}$ & $\begin{array}{l}\text { Catechol, p-hydroxybenzaldehyde, dihydroxyphenylacetic acid, tyrosol, p-hydroxybenzoic acid, } \\
\text { dihydroxybenzoic acid, vanillic acid, phloretic acid, pinoresinol, secoisolariciresinol }\end{array}$ \\
\hline 4. & $\begin{array}{l}\text { Soursop, Graviola, } \\
\text { Brazilian pawpaw }\end{array}$ & Annona muricata & $\begin{array}{l}\text { Annonaceous acetogenins (annomontacin, annomuricatins, annomuricins, annomutacin, } \\
\text { annonacin, annonacinone annocatalin, annohexocin, annomonicin, annopentocin, muricins } \\
\text { muricatetrocin, longifolicin epomuricenins, epomurinins, gigantetrocins, etc) }\end{array}$ \\
\hline 5. & Tomatoes & $\begin{array}{l}\text { Lycopersicon } \\
\text { esculentum Mill }\end{array}$ & Lycopene \\
\hline 6. & Cabbage & Brassica oleracea & Indole-3-carbinol \\
\hline 7. & Soya beans & (Glycine max) & Isoflavones (daidzein and genistein) \\
\hline 8. & Green tea & Camellia sinensis & $\begin{array}{l}(-) \text { epigallocatechin gallate (EGCG), (-) epicatechin, (-) epicatechin-3-gallate and (-) } \\
\text { epigallocatechin -3-gallate }\end{array}$ \\
\hline 9. & Chili pepper & Capsicum spp & Capsaicin \\
\hline 10. & Citrus fruits & Citrus spp & Pectins, Limonoids \\
\hline
\end{tabular}

schweinfurthii Engl oil contained ten polyphenols, namely; catechol, p-hydroxybenzaldehyde, dihydroxyphenylacetic acid, tyrosol, p-hydroxybenzoic acid, dihydroxybenzoic acid, vanillic acid, phloretic acid, pinoresinol, secoisolariciresinol with $\mathrm{IC} 50$ of $56 \mu \mathrm{L}$ and $\mathrm{IC}_{50}=104$, when assayed by xanthine oxidase and 2-deoxyguanosine method, respectively (Table 1 ).

\section{Discussion}

The potent antioxidant and radical scavenging capacity observed, is a good reflection of the polyphenol composition of Canarium schweinfurthii Engl fruit oil, Dacryodes edulis and Moringa oleifera extracts (Table 1). Biological activities such as these have been credited with chemoprevention of diseases like cancer, which result, at least in part, from oxidative damage $[4,8]$. The difference in the polyphenol composition and antioxidant activities of different parts of M.oleifera, suggests that different parts of the same plant may have significantly different anticancer activity.

Quercetin and quercetin derivatives as detected in these Nigerian foods have been reported to inhibit prostate cancer colony melanoma growth, and act as proapoptotic agent $[9,10]$. Similarly, ellagic acid, an oxidation product of gallic acid, catechol, kaempferol and its derivatives which were detected in these Nigerian foodstuffs have undergone different levels of study as possible prostate cancer chemopreventive agents, with promising results, including potent antimutagenesis, antitumour and antimetastasis properties[3,11]; effects that are also relevant to prostate cancer control and chemoprevention [3,8-11]. Besides, many of the polyphenols and lignans detected in Canarium schweinfurthii Engl fruit oil have been credited with, among others, prostate cancer chemoprevention activities $[3,4,7,12]$.

In addition to these foodstuffs, other food materials widely reported to posses prostate cancer chemopreventive compounds are also grown in Nigeria (table 1). These include tomatoes which contains the powerful antioxidant and anti-prostate cancer agent, lycopene; cabbage which contains indole-3-carbinol; citrus fruits which contains pectin; Graviola or Soursop (Annona muricata) which contains the annonaceous acetogenins, soya beans (Glycine max) which contains the isoflavones, daidzein and genistein; Capsicum spp which contains capsaicin, and Camellia sinensis which contains (-) epigallocatechin gallate (EGCG), (-) epicatechin, (-) epicatechin-3-gallate and (-) epigallocatechin -3-gallate [2-4,8]. Therefore, though prostate cancer is historically more prevalent in males of African extraction, the incidence can be dramatically reduced, and the age of onset drastically increased, if the population at risk consumes the right kinds of foods in the right proportion, beginning early in life, especially as prostate cancer has a gestation period of about 50 years.

\section{Acknowledgements}

This article has been published as part of Infectious Agents and Cancer Volume 6 Supplement 2, 2011: Proceedings of the First Biennial Conference on the Science of Global Prostate Cancer Disparities in Black Men. The full contents of the supplement are available online at http://www. infectagentscancer.com/supplements/6/S2.

\section{Competing interests}

The author declares that he has no competing interests. 


\section{References}

1. GLOBOCAN (2008): Fast Stats: West Africa. WHO/IARC, Lyons; 2010.

2. Adhami VM, Siddiqui IA, Sarfaraz S, Khwaja SI, Hafeez BB, Ahmad N, Mukhtar H: Effective Prostate Cancer Chemopreventive Intervention with Green Tea Polyphenols in the TRAMPModel Depends on the Stage of the Disease. Clin Cancer Res 2009, 15(6):1947-1956.

3. Lewis JE, Soler-VilÂ'a H, Clark PE, Kresty LA, Allen GO, Hu JJ: Intake of Plant Foods and Associated Nutrients in Prostate Cancer Risk. Nutr Cancer 2009, 61(2):216-224.

4. Siddiqui IA, Afaq F, Adhami VM, Mukhtar H: Prevention of prostate cancer through custom tailoring of chemopreventive regimen. Chemico-Biol Interact 2008, 171(2):122-132.

5. Atawodi SE, Atawodi JC, Idakwo P, Pfundstein B, Haubner R, Wurtele G, Spiegelhalder B, Bartsch H, R W, Owen RW: Evaluation of the Polyphenol Composition and Antioxidant Activity of African Variety of Dacryodes edulis (G.Don) H.J Lam Fruit. J Med Food 2009, 12(6):1321-1325.

6. Atawodi SE, Atawodi JC, Idakwo GA, Pfundstein B, Haubner R, Wurtele G, Spiegelhalder B, Bartsch H, R W, Owen RW: Evaluation of the Polyphenol Content and Antioxidant Properties of Methanol Extracts of the Leaves, Stem And Root Barks Of Moringa Oleifera, Lam. J Med Food 2010, 13(3):710-716.

7. Atawodi SE: Polyphenol Composition and in vitro Antioxidant Potential of Nigerian Canarium schweinfurthii Engl. Oil. Adv Biol Res 2010, 4(6):314-322.

8. Johnson JJ, Bailey HH, Mukhtar H: Green tea polyphenols for prostate cancer chemoprevention: a translational perspective. Phytomed 2010, 17(1):3-13.

9. Gibellini L, Pinti M, Nasi M, Montagna JP, Biasi SD, Erika Roat E, Bertoncelli L, Cooper EL, Andrea Cossarizza A: Quercetin and Cancer Chemoprevention. eCAM Advance Access 2010, doi:10.1093/ecam/neq053, 1-14.

10. Nair HK, Rao KV, Aalinkeel R, Mahajan S, Chawda R, Schwartz SA: Inhibition of prostate cancer cell colony formation by the flavonoid quercetin correlates with modulation of specific regulatory genes. Clin Diagn Lab Immunol 2004, 11(1):63-69.

11. Carolyn Bell, Susan Hawthorne: Ellagic acid, pomegranate and prostate cancer - a mini review. J Pharm Pharmacol 2008, 60(2):139-144.

12. Owen RW, Mier W, Giacosa A, Hull WE, Spiegelhalder B, Bartsch H: Identification of lignans as major components in the phenolic fraction of olive oil. Clin Chem 2000, 46(7):976-988.

doi:10.1186/1750-9378-6-S2-S9

Cite this article as: Atawodi: Nigerian foodstuffs with prostate cancer chemopreventive polyphenols. Infectious Agents and Cancer 2011 6(Suppl 2):S9.

\section{Submit your next manuscript to BioMed Central and take full advantage of:}

- Convenient online submission

- Thorough peer review

- No space constraints or color figure charges

- Immediate publication on acceptance

- Inclusion in PubMed, CAS, Scopus and Google Scholar

- Research which is freely available for redistribution 